\title{
Universal Access to Malaria Prevention, Diagnosis and Treatment as a Strategy toward Disease Control and Elimination: A Critical Look at Northeastern Nigeria
}

\author{
Abdullahi Saddiq ${ }^{* \#}$, Jalal-Eddeen Abubakar Saleh${ }^{1}$, Alemu Wondimagegnehu², \\ Rex Mpazanje1, Bala Mohammed Audu ${ }^{3}$ \\ ${ }^{1}$ Communicable and Non-Communicable Diseases, World Health Organization, Abuja, Nigeria \\ ${ }^{2}$ Fmr. WR, World Health Organization Country Office, Abuja, Nigeria \\ ${ }^{3}$ National Malaria Elimination programmes, Abuja, Nigeria \\ Email:"saddiqa@who.int
}

How to cite this paper: Saddiq, A., Saleh, J.-E.A., Wondimagegnehu, A., Mpazanje, R. and Audu, B.M. (2019) Universal Access to Malaria Prevention, Diagnosis and Treatment as a Strategy toward Disease Control and Elimination: A Critical Look at Northeastern Nigeria. Open Access Library Journal, 6: e5659.

https://doi.org/10.4236/oalib.1105659

Received: August 2, 2019

Accepted: November 23, 2019

Published: November 26, 2019

Copyright (๑) 2019 by author(s) and Open Access Library Inc.

This work is licensed under the Creative Commons Attribution International License (CC BY 4.0).

http://creativecommons.org/licenses/by/4.0/

\begin{abstract}
Background: As early as 2008 there was a call by the United Nations Secretary General to halt malaria death by ensuring universal coverage of malaria interventions to be attained by 2010 . This was echoed by the World Health Assembly in 2015 by adopting the Global Technical Strategy or malaria 2016-2030 with universal access to malaria prevention, diagnosis and treatment as one of its three pillars. This study had a critical look at the supply and distribution of Artemisin-based Combination Therapy, Rapid Diagnostic Tests and Long Lasting Insecticide Treated Nets in 2017 with a view to critique the universal coverage of these commodities in Adamawa, Bauchi, Borno, Gombe, Taraba and Yobe States in the northeastern geopolitical region of Nigeria. Method: This is a quantitative cross-sectional study using secondary data. The research analyzed the data of malaria intervention commodities received by state malaria elimination programmes from six states across the northeast zone between January and December 2017. Results: The study result showed that RDTs were received and distributed in four of the six states and one state did not receive or distribute any. Commodities for treatment (ACTs) received and distributed showed that only one state had a significant supply and distribution of the commodity, two states had minimal supply and distribution while the other three states had insignificant quantities that did not match the RDT supply and the state that had the highest supply/distribution was the only state supported by the global fund in the northeast zone in 2017. Only one state had a significant quantity of LLINs
\end{abstract}


distributed in 2017. Conclusion: The government of Nigeria and collaborating partners have made concerted efforts to improve access to ACTs, RDTs and LLINs with improvement in levels of intervention across the country. This study however clearly demonstrates the need to intensify efforts in making universal access possible in northeastern Nigeria so that the objectives of the National Malaria Strategic Plan 2014-2020 can be achieved. This comes at a time when donor funding is at cross-roads.

\section{Subject Areas}

Epidemiology, Infectious Diseases, Nursing, Public Health

\section{Keywords}

Malaria, Long-Lasting Insecticidal Nets, Universal Access, National Malaria Elimination Programme, Adamawa, Bauchi, Borno, Gombe, Taraba, Yobe, Nigeria

\section{Background}

"The malaria burden is the highest in countries with the lowest human development, within countries in the least developed and poorest areas, and within populations among the most disadvantaged. Malaria is both a result and a cause of a lack of development" [1].

There was a call in 2006 for "Universal Access to HIV and AIDS, Tuberculosis and Malaria Services by a United Africa by 2010" which was as a result of strengthened country programme leadership, greater political commitment, and stronger global partnership and coordination which was central to progress [2]. In the same year Ministers of Health of the African Region debated the challenges faced in controlling malaria and realised that the power of a government's good stewardship and partnerships at all levels was the recipe to strengthen community capacity for effective prevention and control and that success depended upon the universal access to essential technologies and tools [3].

Despite substantial increases in international donor assistance to malaria-endemic countries since 2007, worldwide commitment remained below that needed to mount effective coverage of prevention and clinical management strategies necessary to substantially affect disease burden [4]. However, national government spending and individual or household spending on malaria prevention and treatment have always been in place, although to different degrees reaching all aspects of preventive and curative care, is difficult to quantify as malaria-specific [5]. An analysis of funding for malaria control from 2006 to 2010 by Pigott et al. in 2012 showed that globally inadequate levels of funding persisted, and that there were large inequalities, which varied in importance and ease of resolution, whether through increased government support or international assistance [6]. 
In 2008, the United Nation (UN) Secretary General had set an ambitious objective: to halt malaria deaths by ensuring universal coverage of malaria interventions by 2010 [7] [8]. In the light of progress made by 2010, Roll Back Malaria (RBM) programme updated the Global Malaria Action Plan (GMAP) targets in June 2011. In maintaining an overall vision of a "malaria-free world", the targets set then were to reduce global malaria deaths to near zero by end-2015; reduce global malaria cases by 75\% from 2000 levels by end-2015; and eliminate malaria by end-2015 in 10 new countries since 2008, including in the WHO European region and were to be met by: achieving and sustaining universal access to and utilization of preventive measures; achieving universal access to case management in the public and private sectors and in the community (including appropriate referral); and accelerating the development of surveillance systems [8]. This was followed by many high-level resolutions and political commitments, and considerable amounts of money invested ni malaria control [1]. But gains made were fragile, as donor funding was not secure and even insufficient to achieve and maintain universal coverage of basic interventions in all malaria endemic countries [9]. Analysis by Bhatt et al. in 2015 demonstrated that malaria interventions at the time have been highly effective at reducing prevalence and incidence across the African continent and provided strong support for sustaining and increasing access to these interventions as a cornerstone of post-2015 control strategies [10]. Malaria prevention and control efforts both contribute to and benefit from sustainable development and the objectives of reducing the disease burden and eliminating malaria are intrinsically linked to most of the Sustainable Development Goals (SDGs), as they were to nearly all of the Millennium Development Goals (MDGs) [11] [12]. The MDG target 6c, which aim to halt and begin to reverse the incidence of malaria and other major diseases by 2015, was achieved for malaria. Worldwide, the number of estimated cases per 1000 habitants at risk of malaria has reduced by $38 \%$ and a mortality reduction by $60 \%$ between $2000-2015$. Similarly, and looking at the Africa region, the number estimated cases per 1000 habitants at risk of malaria has reduced by $42 \%$ and a mortality reduction of $66 \%$ [13]. Linking this achievement with the SDGs, Goal 3 aims to "ensure healthy lives and promote wellbeing for all at all ages", and this is by "achieving UHC including financial risk protection, access to quality essential healthcare services, medicines and vaccines for all." The goal that targets Malaria is 3.3 and is aiming at ending the epidemic of AIDS, TB, Malaria and NTDs by 2030 [14].

Consequently, the $68^{\text {th }}$ WHA in 2015 recognized that malaria interventions were highly cost-effective, yet there was a need to urgently address and overcome the barriers that hindered universal access of at-risk populations to vector-control measures, preventive therapies, quality-assured diagnostic testing and treatment for malaria; adopted the global technical strategy for malaria 2016-2030, with universal access to malaria prevention, diagnosis and treatment as one of its three pillars [15]. Optimizing the delivery of malaria interventions 
was central to progress towards universal health coverage, ensuring healthy lives and promoting wellbeing for all ages, particularly for vulnerable and marginalized populations as malaria is also an important entry point for promoting universal health coverage [11].

WHO defines Universal coverage for malaria vector control as universal access to and use of appropriate interventions by populations at risk of malaria [16]. It is recommended that achieving and maintaining universal Insecticide Treated Nets (ITNs) coverage, countries should apply a combination of mass free net distribution through campaigns and continuous distribution through multiple channels, in particular through antenatal care clinics and the expanded programme on immunization [16] [17] [18]. World Malaria Report 2016 showed that access to vector control has been greatly extended; however, increasing the coverage of chemoprevention, diagnostic testing and treatment requires these interventions to be delivered through health systems that are frequently under-resourced and poorly accessible to those most at risk of malaria [17] [18].

Constraints like increased risk of parasite resistance to established cheap drugs, development assistance being routed largely through public channels whereas affected individuals sought treatment mostly through private sector and ACTs being too expensive for out of pockets spending have impeded access to effective treatments of malaria [19]. In Nigeria, estimates suggest malaria as a disease retards the country's GDP alone by at least 40 per cent annually, costing

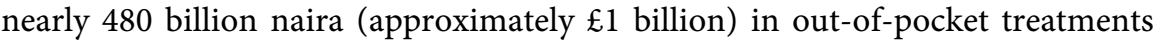
[16] [20]. The problem of maintaining investment in malaria control once the disease is of minor importance is often emphasised because the consequences of donor fatigue are very real and rebound is something potentially devastating, hence reducing present amounts of malaria funding that are providing effective intervention coverage in some countries would be disastrous [21].

In Nigeria, focus shifted from prioritizing the biologically vulnerable as primary target groups for interventions to universal and equitable access of all the population in order to fully materialize the potential of the preventive interventions in its 2009-2013 National Malaria Strategic Plan, with one of the overall objectives involving scaling up of impact nationally [22]. As a follow-up, the 2014-2020 Strategic Plan envisaged that universal coverage was to be achieved in the first five years of the plan [23]. The goal was for at least 80 percent of the targeted population to use appropriate preventive measures by 2020 which was to be attained through the core technical strategies of expanding universal access to insecticide-treated materials including sustained mass distribution of long-lasting insecticidal nets; significantly scaling up indoor residual spraying; and expanding larval source management (larviciding and environmental management); and providing support for intermittent preventive therapy and seasonal malaria chemoprevention [24].

Nigeria has received considerable amounts of external resources particularly 
from the Global Fund (GF), World Bank, USAID and UKAid, which helped the country make gains in malaria control, but more investment is needed to enable the country to attain universal coverage with interventions in order to achieve impact seen in successful sub-Saharan countries [25]. The access indicator for ITNs indicates typical net usage is a key indicator of the effectiveness of the malaria programme in Nigeria [24]. This was shown in the 2015 Malaria Indicator Survey (MIS) which indicated that household ITNs ownership had substantially increased from $8 \%$ in 2008 to $42 \%$ in 2010 , to $50 \%$ in 2013 , and $69 \%$ in 2015 . Survey findings show that 68 percent of mosquito nets in northeastern were obtained through a net distribution campaign One in five households in northeastern (20 percent) report that they obtained mosquito nets from a shop, supermarket, open market, or hawker; households in this zone rely on this source more than any other zone [26].

A worrisome situation depicted in the 2017 World Malaria Report (WMR) was that despite the unprecedented funding for malaria in recent years, the US $\$ 2.7$ billion invested in 2016 accounted for only $41 \%$ of the estimated annual investment required to achieve the GTS goals. Hence funding levels per capita at risk have either plateaued or decreased across most WHO regions relative to the peak years of 2012 or 2013 and it is likely that decreasing funds will lead to gradual deterioration of the coverage and quality of interventions, and eventually to loss of previous gains [18].

This study critically examined the supply and distribution of ACTs, RDTs and LLINs in 2017 with a view of assessing the universal access/coverage of these commodities in Adamawa, Bauchi, Borno, Gombe, Taraba and Yobe States in the northeast geopolitical region of Nigeria.

\section{Method}

Diagnosis and treatment have dominated as the strategic core of contemporary malaria control over the past 40 years involving the use of commodities which include rapid diagnostic tests (RDT) and artemisinin-based combined therapies (ACT) complimented by the use of lasting insecticide-treated nets (LLIN) and indoor residual spraying (IRS) [27]. The "research question-driven" approach of conducting a secondary analysis of existing data [28] was used to analyze data of malaria intervention commodities including RDTs, ACTs and LLINs received and distributed by state malaria elimination programmes from six states across the northeastern Nigeria in 2017.

The states (Figure 1) include Adamawa, Bauchi, Borno, Gombe, Taraba, and Yobe [29]. The study used records of all malaria intervention commodities (RDTs, LLINs, and ACTs) received from RBM partners working in these states; the Save One Million Lives of the Federal Ministry of Health, National Primary Health Care Development Agency, National Malaria Elimination Program, States Ministry of Health and State Primary Health Care Development Agencies. The findings from the study were analysed using the SPSS version 24 . 


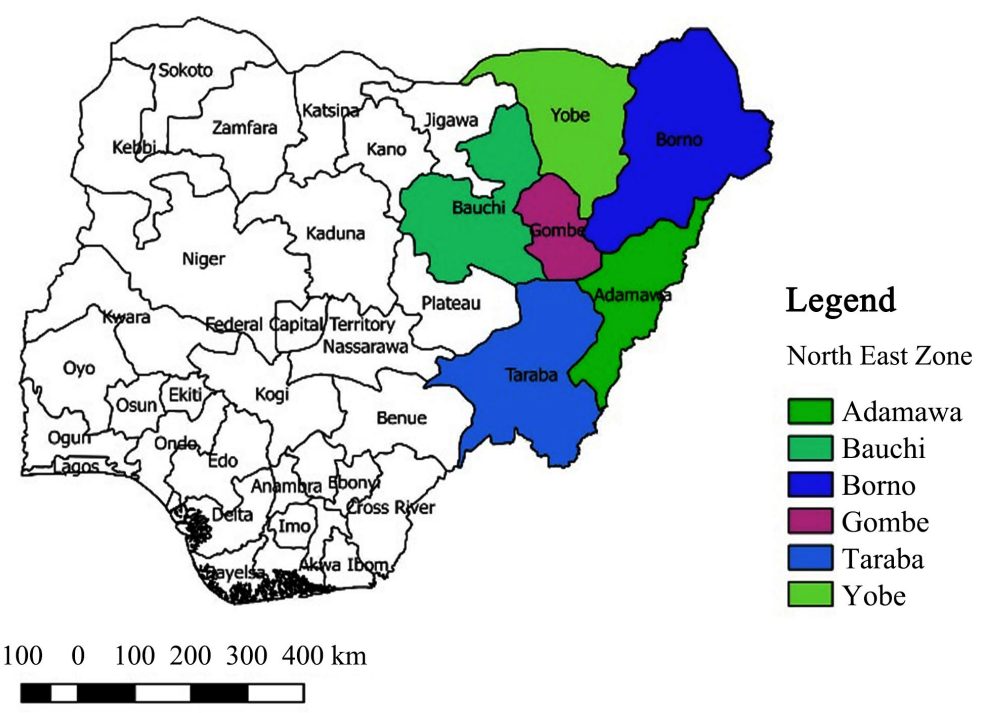

Figure 1. Map of Nigeria showing the six States in the Northeastern Zone.

\section{Result}

The study result showed that some quantity of RDTs were received and distributed in four of the six states (Figure 2), the largest quantity being about 1.5 million RDTs and one state did not receive or distribute any RDTs, while one state (Taraba) received/distributed the least quantity of RDTs. Three of the states (Adamawa, Borno and Yobe) had RDTs as part of the emergency humanitarian intervention, while Bauchi had RDTs due to GF support. The states without support had non or insignificant quantities of RDTs.

The supply/distribution was not any better for treatment (ACTs) whereby only one state, had a significant supply and distribution of the commodity, two states had minimal supply and distribution while the other three states had insignificant quantities that do not match the RDT supply (Figure 3 and Table 1). The state with the highest ACT supply/distribution was the only state supported by Global Fund for malaria control activities in the northeastern region in 2017.

The use of LLINs especially in malaria endemic countries is considered as one of the most cost-effective measures towards malaria prevention [30] [31]. This study showed that only one state had a significant quantity of LLINs distributed in 2017 (Figure 4 and Table 2) and this was because the state had a replacement campaign in 2017.

\section{Discussions}

Since the beginning of the millennium substantial gains have been made in the fight against malaria, most of which have been directly attributed to increasing coverage of core malaria control measures, notably in sub-Saharan Africa where transmission is the most intense, despite which the implementation of malaria control activities falls short of universal health coverage (UHC) targets and malaria continues to pose a major public health challenge in countries where it remains endemic [31] [32] This is demonstrated by the outcome of the study 
which showed that the access to malaria commodities in the northeastern of $\mathrm{Ni}$ geria fell short of what was required for universal access/coverage in the six states in 2017.

Table 1. Showing ACTs received and distributed across the NE zone in 2017.

\begin{tabular}{|c|c|c|c|}
\hline & & ACTs Received & ACTs Distributed \\
\hline & & Mean & Mean \\
\hline \multirow{6}{*}{ State } & Adamawa & 67,570 & 67,250 \\
\hline & Bauchi & $2,604,555$ & $2,410,750$ \\
\hline & Borno & 360,866 & 203,611 \\
\hline & Gombe & 0 & 0 \\
\hline & Taraba & 26,000 & 26,000 \\
\hline & Yobe & 288,828 & 288,828 \\
\hline
\end{tabular}

Table 2. Showing LLINs received and distributed across the NE zone in 2017.

\begin{tabular}{|c|c|c|c|}
\hline & & LLINs Received & LLINs Distributed \\
\hline & & Mean & Mean \\
\hline \multirow{6}{*}{ State } & Adamawa & $2,620,851$ & $2,611,300$ \\
\hline & Bauchi & 181,880 & 172,880 \\
\hline & Borno & 48,000 & 15,800 \\
\hline & Gombe & 288,828 & 0 \\
\hline & Taraba & 0 & 0 \\
\hline & Yobe & 185,000 & 185,000 \\
\hline
\end{tabular}

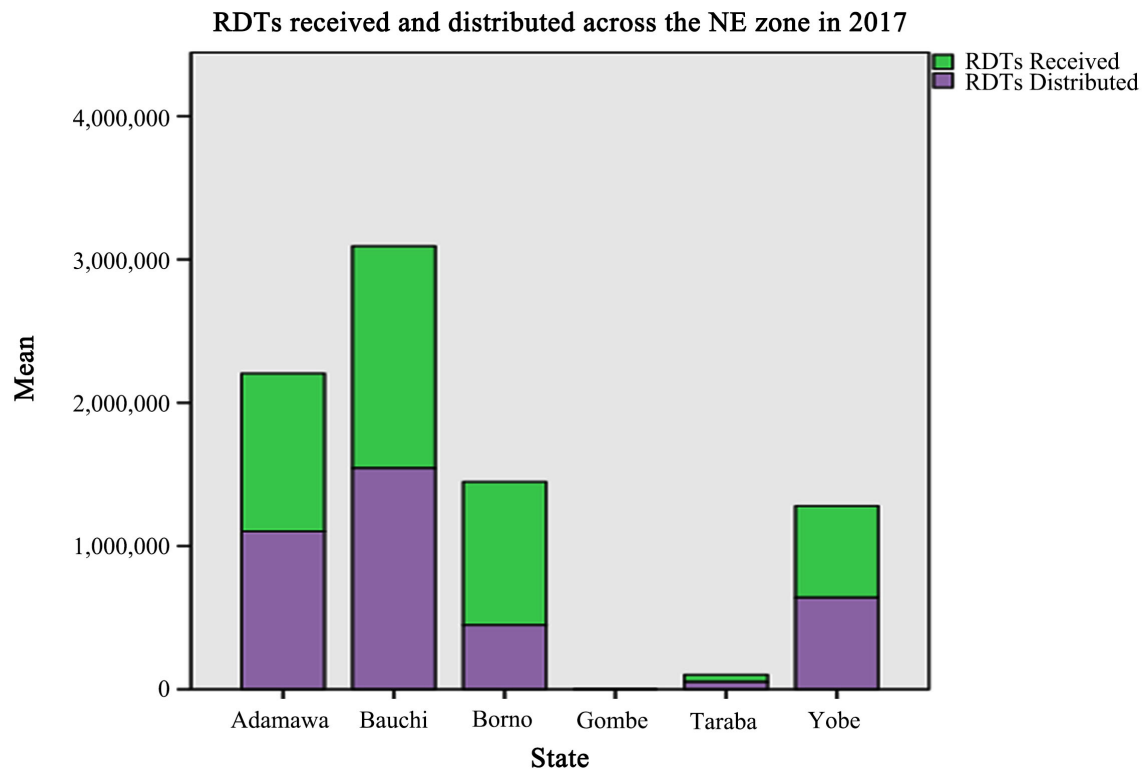

Figure 2. RDTs received and distributed across the NE zone in 2017. 


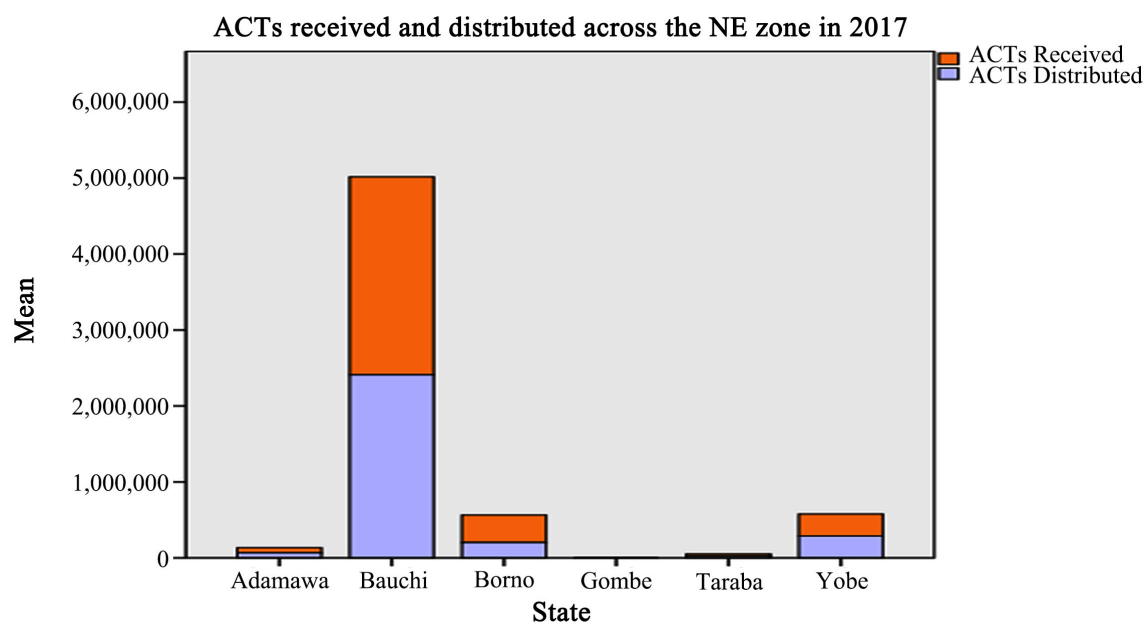

Figure 3. Showing ACTs received and distributed across the NE zone in 2017.

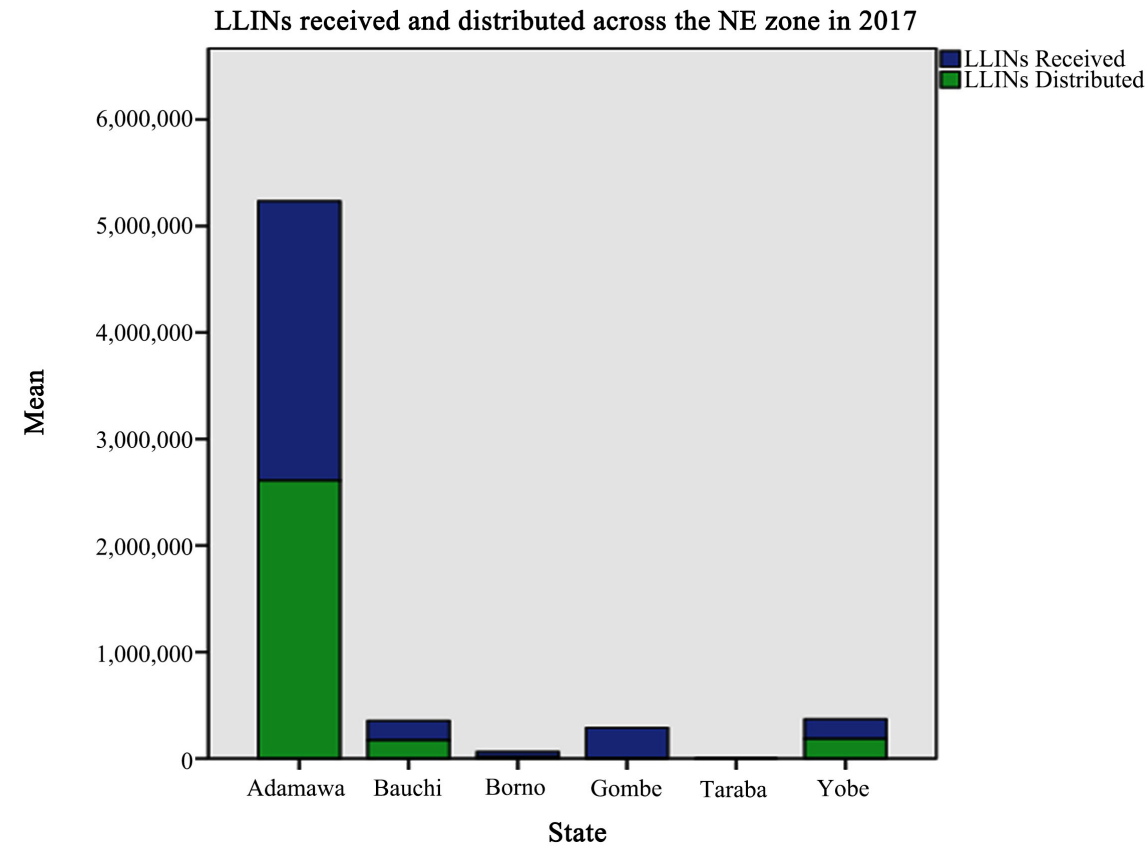

Figure 4. Showing LLINs received and distributed across the NE zone in 2017.

As observed by Saleh, economies can't grow when the population doesn't have access to healthcare. Saleh added that "Ill-health has a micro impact on household income, the success of small businesses productivity in general," [20]. Similarly, "the macro impact is that GDP goes down." The health systems in northeastern Nigeria, weakened by nearly a decade of insecurity, has affected the distribution of malaria commodities. This negative effect was more, especially in four states; Borno, Yobe, Adamawa and Taraba. This observation was highlighted by Saleh [20] that "insecurity, turmoil and war shatter health systems." and this adversely affects public health interventions. A situation that required adequate supply/distribution of commodities which was not met as shown by the findings of this study. A critical factor determining the potential to reach 
UHC will be the financial resources invested in malaria from domestic and international sources over the years [33]. This study brings to light the fact that these sources of funding must be improved to make any headway towards universal access to malaria intervention commodities in northeastern Nigeria. This is because 13 out of 37 Nigerian states have no reported donor funding for malaria control efforts, including four of the six poorest states in the northeastern that have high malaria burdens (Adamawa, Taraba, Borno, Yobe) and providing sustained funding to these areas is difficult due to the fragile political and security situation that limits access, and this lack of funding certainly means coverage will remain low [34] [35].

Providing universal access to accurate malaria diagnostic testing for all patients suspected of having malaria is the ultimate goal of any national malaria control programme [36]. Hence following a major paradigm change of a progressive shift from presumptive treatment towards parasitological confirmation prior to treatment, particularly in areas of high malaria transmission required an increase in the procurement and use of rapid diagnostic tests [30]. For rational use of ACTs to be improved, WHO recommended in 2010 that all suspected cases of malaria should have parasitological confirmation before treatment; and central to implementing this policy change are RDTs which are intended to improve the management of suspected malaria cases; increasing the use of first-line antimalarials in patients with confirmed malaria; and encouraging the diagnosis and appropriate treatment of patients without malaria [37]. This study shows that RDTs received in the northeastern Nigeria were mainly in the 3 states getting support due to the humanitarian intervention and one state was getting GF support. Those that did not have any support had no or insignificant RDT supply/distribution. A situation that is clearly not "Universal".

Artemisinin-based combination therapy (ACT) is highly effective at treating clinical malaria and has contributed significantly to major reductions $(\sim 40 \%)$ in the global burden of malaria since being introduced in the 2000s [37]. There is significant improvement in the availability, affordability, quality and use of the ACT, especially in the public health service sector. Yet, as noted in a recent publication by Bennett and colleagues, while ACT coverage in children less than 5 years old with fever and $P$. falciparum infection increased during the 2003-2015 interval, treatment of those in need reached only $20 \%$ by 2015 [38]. This is more alarming in northeastern Nigeria where only one out of six states had a significant supply/distribution of the ACTs.

ITNs are the mainstay of malaria prevention efforts, particularly in sub-Saharan Africa where the use of ITNs has increased substantially over the last decade but major coverage gaps remain: in 2015, an estimated $47 \%$ of the population at risk of malaria did not sleep under a treated net [39]. This study is distinctive as it shows that the northeastern Nigeria can serve as an example of places where such gaps are found and that access to the core prevention tools must be significantly expanded, particularly in countries with ongoing malaria transmission and areas like this in order to achieve universal access/coverage. 


\section{Conclusion}

Universal access to malaria intervention commodities and tools is key not only to malaria control and elimination but to universal health coverage as a whole. The government of Nigeria and collaborating partners have made concerted efforts to improve access to these crucial commodities with improvement in levels of intervention across the country. This study however clearly demonstrates the need to intensify efforts in making universal access possible in northeastern $\mathrm{Ni}$ geria so that the objectives of the National Malaria Strategic Plan 2014-2020 can be achieved. However, with the appreciable improvement in security in the northeastern Nigeria, it is expected that the health systems will improve, and so also the delivery of Malaria commodities for the country to achieve the SDG and GTS 2030 targets. Saleh made the same assertion that as security is coming back to the Africa continent, so is the health systems [20]. Although donor funding is at cross-roads, there is the need for global players in the fight against Malaria to once again support this noble goal as it is efforts such as that of the Roll Back Malaria campaign that resulted in a reduction in the prevalence of Malaria in Nigeria from 42 per cent to 27 per cent [20] [37].

\section{Conflicts of Interest}

The authors declare no conflicts of interest regarding the publication of this paper.

\section{References}

[1] UNDP and RBM (2013) Multisectoral Action Framework for Malaria.

[2] United Nations (2008) Resolution Adopted by the General Assembly on 22 December 2008 Sixty-Third Session Agenda Item 43. A/RES/63/234.

[3] WHO (2011) World Malaria Report 2011.

[4] WHO (2015) Sixty-Eight World Health Assembly WHA68.2 Agenda Item 16.222 May 2015.

[5] Malaria Funding \& Resource Utilization (2010) The First Decade of Roll Back Malaria. Progress\& Impact Series. Number 1.

[6] Fact Sheets on Malaria and The SDGs (2015) One of a Series of Fact Sheets to Accompany the Briefing Paper Lessons Learned from Responding to Malaria Globally: A Prototype for Sustainable Development.

[7] Snow, R.W., Okiro, E.A., Gething, P.W., et al. (2010) Equity and Adequacy of International Donor Assistance for Global Malaria Control: An Analysis of Populations at Risk and External Funding Commitments. The Lancet, 376, 1409-1416. https://doi.org/10.1016/S0140-6736(10)61340-2

[8] Pigott, D.M., Atun, R., Moyes, C.L., et al. (2012) Funding for Malaria Control 2006-2010: A Comprehensive Global Assessment. Malaria Journal, 11, Article No. 246. https://doi.org/10.1186/1475-2875-11-246

[9] Wilson, P. and Aizenman, Y. (2012) Value for Money in Malaria Programming: Issues and Opportunities. CGD Working Paper 291. Center for Global Development, Washington DC. http://www.cgdev.org/content/publications/detail/1426120 
https://doi.org/10.2139/ssrn.2102718

[10] WHO Regional Committee for Africa (2016) Sixty-Sixth Session Addis Ababa, Federal Democratic Republic of Ethiopia. Agenda Item 15, 19-23 August 2016. AFR/RC66/14.

[11] Sambo, L.G. (2007) Defining and Defeating the Intolerable Burden of Malaria III. Progress and Perspectives (Foreword). The American Journal of Tropical Medicine and Hygiene, 77, 3. https://doi.org/10.4269/ajtmh.2007.77.iii

[12] (2000) Millenium Development Goals. https://www.undp.org/content/undp/en/home/sdgoverview/mdg goals.html

[13] WHO (2018) High Burden to High Impact: A Targeted Malaria Response. https://www.who.int/malaria/publications/atoz/high-impact-response/en

[14] (2015) Sustainable Development Goals. https://www.un.org/ga/search/view doc.asp?symbol=A/RES/70/1\&Lang=E

[15] FMOH (2009) National Malaria Control Program Strategic Plan 2009-2013.

[16] Federal Republic of Nigeria (2013) National Malaria Strategic Plan 2014-2020.

[17] Adeyi, O. and Atun, R. (2010) Universal Access to Malaria Medicines: Innovation in Financing and Delivery. The Lancet, 376, 1869-1871. https://doi.org/10.1016/S0140-6736(10)61189-0

[18] Bhatt, S., Weiss, D.J., Cameron, E., et al. (2015) The Effect of Malaria Control on Plasmodium falciparum in Africa between 2000 and 2015. Nature, 526, 207-211. https://doi.org/10.1038/nature15535

[19] Snow, R.W. and Marsh, K. (2010) Malaria in Africa: Progress and Prospects in the Decade since the Abuja Declaration. The Lancet, 376, 137-139. https://doi.org/10.1016/S0140-6736(10)60577-6

[20] Imperial College London (2019) Africa Innovators. http://www.imperial.ac.uk/be-inspired/magazine/issue-46/african-innovators

[21] NMEP (2014) Malaria Business Plan 2014-2017.

[22] Global Malaria Programme (2017) Achieving and Maintaining Universal Coverage with Long-Lasting Insecticidal Nets for Malaria Control.

[23] WHO (2016) World Malaria Report 2016.

[24] National Population Commission (NPC) [Nigeria] and ICF International (2014) Nigeria Demographic and Health Survey 2013. NPC and ICF International, Abuja and Rockville.

[25] WHO (2017) World Malaria Report 2017. https://www.who.int/malaria/publications/world-malaria-report-2017/en/

[26] Saleh, J.-E.A., Nemecek, J. and Jones, C. (2015) Antenatal Care Services and Neonatal Tetanus: An Outlook at the Northeastern Nigeria. Paediatric Infectious Diseases Journal, 7, 1-32. https://doi.org/10.1016/j.pid.2015.03.001

[27] Cheng, H.G. and Philips, M.R. (2014) Research Methods in Psychiatry. Secondary Analysis of Existing Data: Opportunities and Implementation. Shanghai Archives of Psychiatry, 26, 371-375.

[28] Baird, K. (2017) Malaria Control by Commodities without Practical Malariology. BMC Public Health, 17, 590. https://doi.org/10.1186/s12889-017-4454-x

[29] World Health Organization (2014) Global Fund Concept Note Development. WHO Policy Brief. WHO/HTM/GMP/2014.1.

[30] Saleh, J.-E.A., Saddiq, A. and Uchenna, A.A. (2018) LLIN Ownership, Utilization, and Malaria Pre-Valence: An Outlook at the 2015 Nigeria Malaria Indicator Survey. 
Open Access Library Journal, 5, e4280. https://doi.org/10.4236/oalib.1104280

[31] Patouillard, E., Griffin, J., Bhatt, S., et al. (2017) Global Investment Targets for Malaria Control and Elimination between 2016 and 2030. BMJ Global Health, 2, e000176. https://doi.org/10.1136/bmjgh-2016-000176

[32] WHO (2011) Universal Access to Malaria Diagnostic Testing: An Operational Manual. https://www.who.int/malaria/publications/atoz/9789241502092/en/

[33] OCHA Nigeria (2017) Humanitarian Needs Overview 2017.

[34] Malaria Consortium (2017) Advocacy Brief. https://www.malariaconsortium.org/resources/publications/add-issue/Malaria

[35] Scott, N., Hussain, S.A., Martin-Hughes, et al. (2017) Maximizing the Impact of Malaria Funding through Allocative Efficiency: Using the Right Interventions in the Right Locations. Malaria Journal, 16, Article No. 368. https://doi.org/10.1186/s12936-017-2019-1

[36] Bruxvoort, K.J., Baptiste Leurent, B., Chandler, C.I.R., et al. (2017) The Impact of Introducing Malaria Rapid Diagnostic Tests on Fever Case Management: A Synthesis of Ten Studies from the ACT Consortium. The American Journal of Tropical Medicine and Hygiene, 97, 1170-1179. https://doi.org/10.4269/ajtmh.16-0955

[37] National Malaria Elimination Programme (NMEP), National Population Commission (NPopC), National Bureau of Statistics (NBS), and ICF International (2016) Nigeria Malaria Indicator Survey 2015. NMEP, NPopC, and ICF International, Abuja and Rockville.

[38] Steketee, R.W. and Eisele, T.P. (2017) Watching the Availability and Use of Rapid Diagnostic Tests (RDTs) and Artemisinin-Based Combination Therapy (ACT). Malaria Journal, 16, Article No. 165. https://doi.org/10.1186/s12936-017-1821-0

[39] World Health Organization (2017) World Malaria Day 2017: Malaria Prevention Works Let's Close the Gap. WHO/HTM/GMP/2017.6. 